\title{
Methods Used in Smoking Cessation and Reduction Attempts: Findings from Help-Seeking Smokers
}

\author{
Marianne Lund $\mathbb{D}$ and Elisabeth Kvaavik \\ Norwegian Institute of Public Health, Oslo, Norway \\ Correspondence should be addressed to Marianne Lund; marianne.lund@fhi.no
}

Received 14 October 2020; Revised 17 February 2021; Accepted 21 February 2021; Published 9 March 2021

Academic Editor: Haniki Mohamed

Copyright (c) 2021 Marianne Lund and Elisabeth Kvaavik. This is an open access article distributed under the Creative Commons Attribution License, which permits unrestricted use, distribution, and reproduction in any medium, provided the original work is properly cited.

\begin{abstract}
In addition to traditional smoking cessation methods like nicotine replacement therapy (NRT), new methods such as mobile applications and e-cigarettes have been added to the toolbox. The purpose of this study was to examine which methods smokers currently use in quit or reduction attempts and map characteristics of users of the various methods. In this study, participants were smokers who visited a website or called a quit line for smoking cessation and who were currently in quit or reduction attempts $(N=740)$. Data were collected in Norway in 2013-2017 through a web survey. Most smokers were currently trying to quit, and the most frequently used methods were a smoking cessation app for mobile phones, nicotine replacement therapies (NRTs), and e-cigarettes. Logistic regression analyses identified older daily smokers with high cigarette consumption as NRT users, while the users of a cessation app were younger females. The use of e-cigarettes was associated with older, low educated smokers with low cigarette consumption. The use of the mobile phone app was associated with having made several recent quit attempts. The study provides insight into help-seeking smokers' preferences for smoking cessation methods and user characteristics. This knowledge is relevant for further work in smoking cessation planning and policies.
\end{abstract}

\section{Introduction}

Smoking cessation in the adult population is essential to accelerate the reduction in smoking-related morbidity and mortality. In Norway, nearly one in ten adults aged between 16 and 79 years were daily smokers in 2019 and a similar proportion was occasional smokers [1]. Smoking prevalence in the youth population (13-15 years) was below 3\% in 2019 [2], indicating positive prospects for decreasing smokingrelated deaths. On the European tobacco control scale, Norway ranks as number five, but with a low score on tobacco treatment [3]. As many as $75 \%$ of smokers in Norway have an intention to quit, which indicates a potential for increased quitting activity [4]. Increasing successful smoking cessation in the adult population will improve population health substantially, but empirical evidence shows that many smokers struggle to quit.

In general, unassisted quitting is the most common route to smoking cessation, although studies indicate that some form of evidence-based smoking cessation aid is better than no aid, and multiple methods may increase the chances of successfully quitting compared to the use of a single method [5-7]. Several methods or cessation aids are available for smokers who want to quit, including nicotine replacement therapy (NRT), prescription medication (bupropion/varenicline), behavioral counseling and quit lines, apps, and websites for smoking cessation. Financial incentives have also been used to increase quit rates, improving smoking cessation [8]. In Norway, NRT has been available for over-thecounter sales since 2003, and an intervention study with free smoking cessation medication in addition to standard cessation counseling for heavy smokers is ongoing.

In the last decade, e-cigarette use has increased and ecigarettes have become an additional smoking cessation aid $[9,10]$. In Norway, the highest share of e-cigarette users is found among former and daily smokers. Reported reasons for use are better health and stigma from smoking combustible cigarettes $[1,11]$. E-liquid with nicotine is not presently allowed to be sold in Norway, but the ban is expected to be lifted in 2021, in line with the EU's Tobacco Product 
Directive. In 2019, the prevalence of daily snus use (moist oral tobacco) was $13 \%$ in Norway and use was concentrated among young males. Daily cigarette smoking was $9 \%$, with the highest rate among people 50 years or older. The availability of an alternative tobacco product possibly plays a role in smoking cessation in Norway and Sweden [12, 13]. The use of NRT, prescription medication like varenicline, and ecigarettes increases success rates in smoking cessation interventions and randomized control trials (RCT) [14-16]. Also, combining several NRT products results in higher long-term quit rates than using a single NRT product [17].

An increase in the use of assistance for smoking cessation has been reported previously, as well as increased internet searches for information about smoking cessation aids [7, 18]. However, smokers' preferences for smoking cessation methods are gradually changing over time, with increasing quit attempts without any assistance and higher use of e-cigarettes [19].

Smokers seeking assistance for smoking cessation are more likely to be women, older smokers, and heavy smokers [7]. A recent study found that younger smokers, in addition to heavier smokers and those with previous quit attempts, were more willing than older smokers to use an evidencebased smoking cessation method [20]. Smokers with high consumption of cigarettes have a stronger preference for choosing pharmacotherapy than do light smokers [7, 20, 21].

Quit success rates, duration of use, reduced side effects, and price are important factors for smoker's preferences for choice of cessation methods [22, 23]. In an experimental study, the likelihood of quit success and reduced side effects were valued as an important feature in the choice of smoking cessation medication, and smokers were willing to pay a higher price for cessation medication with high efficacy [23].

Reasons for using e-cigarettes among smokers are reported as follows: to allow the choice of different flavors, to reduce regular smoking, to save money, and to cause less harm to health than ordinary cigarettes [10]. An online survey investigating preferences for smoking cessation methods reported the highest interest in NRT, websites with quitting advice, and prescription medication [21]. This study also revealed that smokers were least interested in smoking cessation methods involving interpersonal interaction and rather preferred nonsocial cessation methods, such as the internet and pharmacotherapy [21].

Most studies investigating preferred cessation methods normally include just a few alternatives, often excluding ecigarettes. The aim of the present study is to explore a variety of smoking cessation methods used by smokers who plan to quit or reduce smoking, including the use of e-cigarettes. We investigate user characteristics for each smoking cessation method separately; sociodemographic characteristics, smoking behavior characteristics, and quitting plan (reduce or quit). Since the combination of different types of cessation methods is considered more effective, we aim to investigate factors related to the use of multiple cessation methods as compared to the use of one single method.

\section{Materials and Methods}

Callers to a quit line ("Røyketelefonen") and users of a website for tobacco use cessation (http://www.slutta.no, hereafter called "slutta.no"), both run by the Norwegian Directorate of Health, were invited to participate in a study about quitting or reducing tobacco consumption, including cigarettes and/or snus. The present analytical sample includes current smokers with a plan to quit smoking or reduce their cigarette consumption. Current smokers without a quitting plan, former smokers, exclusive snus users, or those only seeking information on tobacco use were excluded from the analytical sample. Callers or website users below 16 years of age were excluded from participation in the study.

Those who agreed to participate gave their email address, either to the quit line operator or via a website link to the study. Recruitment from one source (quit line or website) excluded study participation from the other source. The market research company Norfakta Markedsanalyse AS administered the distribution of the online survey and the data collection. Participation was voluntary, and participants could at any time withdraw their consent and have their data deleted. The research protocol was submitted for consideration to the Regional Committee for Medical and Health Research Ethics, where the project was considered to be beyond the scope of the Health Regulation Act. A notification was made to the Norwegian Social Science Data Service, due to the processing of personal data (no. 35567). Those who completed the survey at each round joined a draw of 10 gift cards for NOK 1500 each, corresponding to $140 €$ or 167 US\$.

2.1. Outcome Measures. Daily and occasional smokers with a current plan to either quit or reduce smoking were asked about their current use of smoking cessation methods. A total of 16 potential cessation methods were listed, with the response options "yes" and "no" in respect of the current use of the listed cessation method. The respondents could register multiple cessation methods. The respondents recruited from the website slutta.no were not given slutta.no as an alternative option in the question about smoking cessation methods. Those recruited from the quit line were given the option of quit line calling due to an additional question regarding the possibility of call back telephone counseling. To gain an equal treatment of the group, we did not include quit line calling in the analysis of smoking cessation methods. The recruitment method indicates that all participants in the study have used at least one smoking cessation method.

The wording of smoking cessation methods was as follows: "In your current attempt to quit or reduce your smoking, do you use some of the following methods?" Methods belonging to the same category were merged. The use of NRT consisted of four items (nicotine gum, patch, lozenge, and inhalator), and those who answered "yes" to at least one item were defined as current users of NRT. Prescription medication was defined as the use of at least one of two medications (Zyban (bupropion) and/or Champix (varenicline)). The use of e-cigarettes constituted one single question, without specifying whether the respondent used e-cigarettes with or without nicotine. The use of snus was covered by one item. The use of smoking cessation applications (apps) consisted of two items, one related to the specific use of the slutta app, developed by the Norwegian Directorate of Health, the other concerning "other cessation apps" in general. Since 232 
participants reported having used the slutta app specifically and 39 reported the use of other apps, this item mainly refers to the use of the slutta app. One item asked about the use of internet sites delivering smoking cessation aids other than the one they were recruited from ("slutta.no"). We also included one question relating to the use of social media platforms such as Facebook, Twitter, and Instagram for smoking cessation aids. One question asked about attendance at smoking cessation courses, but very few reported this option, and the item was therefore omitted in the analysis. The questions are listed in Supplementary Materials, Appendix table (available here).

2.2. Independent Variables. Sociodemographic variables were gender, age, and education level. Participants were grouped into three age groups: $16-29$ years, $30-49$ years, and 50 years or above. Educational level was originally measured on six levels: seven years of primary school, nine years of primary and lower secondary school, one to two years of upper secondary school, the third year of upper secondary school, one to five years of higher education (e.g., bachelor degree), and four or more years of higher education (master's degree or higher). Educational level was grouped for analysis into low educational level (with upper secondary education as the highest level) and high educational level (lower and higher university level).

Daily and occasional smokers were asked about consumption of cigarettes per day and cigarettes per week, respectively. To obtain one common measure for cigarette consumption, cigarettes per day were converted to cigarettes per week for daily smokers. Previous quit attempts measured the number of quit attempts in the last 12 months, categorized into no quit attempts, one quit attempt, and two or more.

The variable multiple methods were constructed by counting all the dichotomous variables of single methods (NRT, e-cigarettes, app, snus, medication, social media, and other internet sites), giving a variable ranging from 0 to 6 . This was recoded into 0 (=no additional method used, i.e., in addition to the use of the website or quit line), 1 (=one additional method used), 2 (=two additional methods used), and 3 (=three or more additional methods used) and for the logistic regression model recoded into a new variable of single versus multiple methods used.

2.3. Statistical Analysis. Differences between the sociodemographic variables, plans, cigarette consumption, and quit attempts and the outcome variable smoking cessation methods were analyzed using logistic regression analysis. The regression models were computed as follows: model 1, sociodemographic variables only; model 2, sociodemographics+smoking status; model 3, sociodemographics+cigarette consumption; model 4, sociodemographics+plans; and model 5, sociodemographics+previous quit attempts. Results are presented in Table 1 as adjusted odds ratios (aOR) with 95\% confidence intervals.

Logistic regression analysis was also used to investigate the association between sociodemographic and smoking behavior characteristics and the use of multiple methods (two or more), compared to a single method. This analysis included only those who reported the use of any of the listed methods $(N=590)$.

\section{Results}

The total sample enrolled 2,517 participants aged 16 years or older in 2013-2017. Most participants were recruited from "slutta.no" (90\%); see Supplementary Materials, Table 5. Our analytical sample consists of smokers who stated that they currently planned to quit smoking or reduce their cigarette consumption $(N=740)$. Descriptive statistics are presented in Table 2.

The total sample did not reflect the population in respect of gender, age, and educational level, with an overrepresentation of females, age group 30-49 years, and higher educated individuals, see Supplementary Materials, Table 5. Former smokers constituted the majority of the total sample (56\%), while about one-third reported current smoking. Eighteen percent were daily snus users. The analytical sample (current smokers) had the same distribution for the demographic variables as the total sample, but fewer used snus in the analytical sample than in the total sample.

3.1. Sociodemographic Characteristics. Among cigarette smokers currently in a quitting or reduction process $(N=740)$, more smokers were planning to quit their smoking $(83 \%)$ than reduce their cigarette consumption $(17 \%)$ (Table 2). The majority were daily smokers (84\%) and about $9 \%$ were dual users of cigarettes (daily and nondaily combined) and snus (daily use only), 58\% smoked more than 70 cigarettes per week, and a majority (86\%) had tried to quit in the last year. One-quarter of the sample (25\%) did not use any of the listed smoking cessation methods. The most common methods used were e-cigarettes (26\%), NRTs (26\%), and cessation apps (37\%). Snus used as a cessation method was reported by seven percent, indicating that approximately half of dual users of cigarettes and snus use snus as a means of quitting.

Older smokers were significantly more likely to have used NRT, e-cigarettes, and cessation medication in their current attempt to quit or reduce smoking (Table 1). The use of snus and smoking cessation apps was more likely in the youngest age group. Gender differences were observed, with a higher odds ratio for females to use the cessation apps and a higher odds ratio for men to use snus. Educational differences were only observed for the use of e-cigarettes, which was more likely among smokers with short education compared to those with long education.

3.2. Smoking Behavior Characteristics. The use of NRT was associated with daily smoking and high cigarette consumption, while the use of smoking cessation medication was only significantly associated with high weekly cigarette consumption. E-cigarette use was associated with occasional smoking and low cigarette consumption. No significant association was observed between the use of snus, other websites, and smoking behavior. The use of social media as a smoking cessation aid was associated with low cigarette consumption, but not with smoking status. 


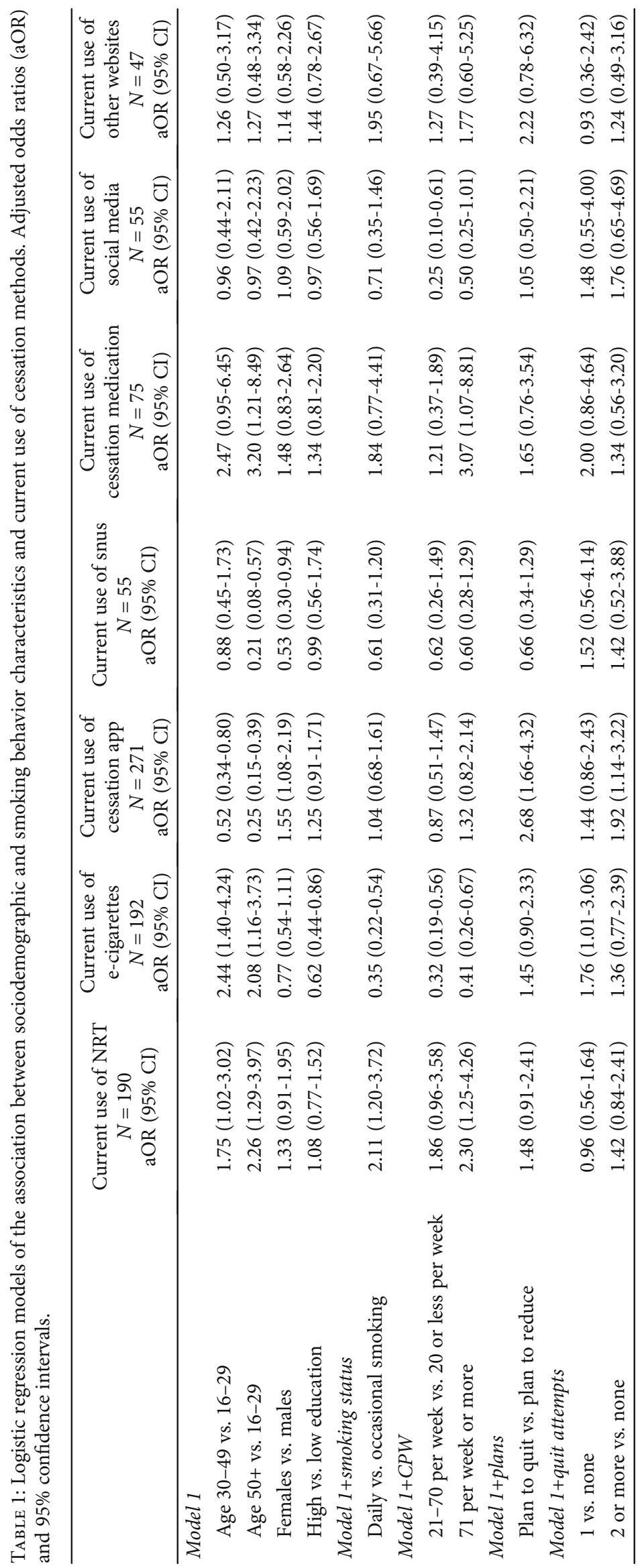


TABLE 2: Descriptive statistics of smokers planning to quit smoking or reduce their cigarette consumption recruited from quit line and web page for smoking cessation, 2013-2017 $(N=740)$.

\begin{tabular}{|c|c|c|}
\hline & \multicolumn{2}{|c|}{$\begin{array}{c}\text { Analytical sample } \\
16-81 \text { years } \\
(N=740)\end{array}$} \\
\hline & $N$ & $\%$ \\
\hline \multicolumn{3}{|l|}{ Gender } \\
\hline Male & 213 & 28.7 \\
\hline Female & 527 & 71.3 \\
\hline \multicolumn{3}{|l|}{ Age group (years) } \\
\hline $16-29$ & 118 & 16.0 \\
\hline $30-49$ & 379 & 51.3 \\
\hline $50-81$ & 242 & 32.8 \\
\hline \multicolumn{3}{|l|}{ Education } \\
\hline Low level & 332 & 44.9 \\
\hline High level & 408 & 55.1 \\
\hline \multicolumn{3}{|l|}{ Smoking status } \\
\hline Daily & 624 & 84.3 \\
\hline Occasional & 116 & 15.7 \\
\hline Former & - & - \\
\hline Never & - & - \\
\hline \multicolumn{3}{|l|}{ Former/never } \\
\hline \multicolumn{3}{|l|}{ Snus use status } \\
\hline Daily & 65 & 8.8 \\
\hline Occasional & 61 & 8.2 \\
\hline Former & 104 & 14.1 \\
\hline Never & 510 & 68.9 \\
\hline \multicolumn{3}{|l|}{ Recruited from } \\
\hline Website & 639 & 86.4 \\
\hline Quit line & 101 & 13.7 \\
\hline \multicolumn{3}{|l|}{ Current plan } \\
\hline Reduce smoking & 126 & 17.0 \\
\hline Quit smoking & 614 & 83.0 \\
\hline No plan & - & - \\
\hline Refuse to answer & - & - \\
\hline \multicolumn{3}{|c|}{ Cigarettes per week (CPW) } \\
\hline$<20$ & 100 & 13.9 \\
\hline $21-70$ & 204 & 28.3 \\
\hline $71+$ & 416 & 57.8 \\
\hline \multicolumn{3}{|c|}{ Previous quit attempts last 12 months } \\
\hline 0 & 100 & 13.5 \\
\hline 1 & 319 & 43.2 \\
\hline $2+$ & 320 & 43.3 \\
\hline \multicolumn{3}{|c|}{$\begin{array}{l}\text { Number of cessation methods used } \\
\text { in addition to quit line/website }{ }^{1}\end{array}$} \\
\hline 0 & 187 & 25.3 \\
\hline 1 & 325 & 43.9 \\
\hline 2 & 158 & 21.4 \\
\hline $3+$ & 70 & 9.5 \\
\hline NRT (4 items) & 190 & 26.0 \\
\hline E-cigarettes (1 item) & 192 & 26.0 \\
\hline
\end{tabular}

TABLE 2: Continued.

\begin{tabular}{lcc}
\hline & \multicolumn{2}{c}{$\begin{array}{c}\text { Analytical sample } \\
\text { 16-81 years } \\
\end{array}$} \\
& $N$ & $\%$ \\
\hline Cessation app (2 items) & 271 & 36.6 \\
Snus (1 item) & 55 & 7.4 \\
Cessation medication (2 items) & 75 & 10.1 \\
Social media (1 item) & 55 & 7.4 \\
Other cessation websites & 47 & 6.4 \\
\hline
\end{tabular}

${ }^{1} 0$ refers to those who answered no use of any of the listed smoking cessation methods.

3.3. Multiple Methods versus One Single Method. Those who planned to quit as opposed to reduce their smoking had higher odds ratios for using multiple smoking cessation methods compared to using only one single method (Table 3). The cessation methods most often used in combination with other methods was the cessation app (64\%). NRT was mentioned by half of those who used multiple cessation methods and e-cigarettes by $38 \%$ (data not shown).

\section{Discussion}

The most frequent method used, the smoking cessation app developed by the Norwegian Directorate of Health, was most prevalent among the young, women, and those with a plan to quit. In general, females are more likely to use smoking cessation aids than men [24], but the association between gender and mobile apps for cessation is unclear. A recent Dutch study found no association between sociodemographic variables and intention to use a mobile app for smoking cessation [25].

Previous research on gender differences in smoking cessation medication use (both NRT and prescription medication) reports higher use among females [26]. In our sample, we did not observe gender differences in NRT or medication use, but a higher odds ratio was observed for snus use as a cessation method among males. A previous study of a representative sample of Norwegian smokers found that snus use was the most commonly reported cessation method used by males, while NRT was the most common cessation method used by females [27].

The finding that smokers with lower educational level are more likely to use e-cigarettes as a smoking cessation method is of interest. There is a strong need for quitting methods which enable increasing quitting activity among vulnerable groups or smokers with low educational level, to overcome social inequalities in smoking-related morbidity and mortality. Systematic review studies on this topic do not support the suggestion that e-cigarettes may reduce smoking inequality $[28,29]$.

Age was the sociodemographic variable that most clearly characterized the users of the various smoking cessation methods. There seems to be a generation gap between the use of NRT, e-cigarettes, and prescription medication on the one hand and smoking cessation apps and snus use on the other. There is some support in the literature for older 
TABLE 3: Logistic regression analysis for multiple use of cessation methods among smokers who reported the use of at least one additional method $(N=590)$. Crude and adjusted odds ratio (aOR).

\begin{tabular}{|c|c|c|}
\hline & $\begin{array}{c}\text { Multiple versus single methods used } \\
\text { Crude OR }\end{array}$ & $\begin{array}{l}\text { Multiple versus single methods used } \\
\text { aOR }(95 \% \mathrm{CI})\end{array}$ \\
\hline \multicolumn{3}{|l|}{ Age } \\
\hline Age $30-49$ vs. $16-29$ & $1.53(0.93-2.51)$ & $1.50(0.88-2.55)$ \\
\hline Age $50+$ vs. $16-29$ & $1.28(0.75-2.20)$ & $1.37(0.77-2.44)$ \\
\hline \multicolumn{3}{|l|}{ Gender } \\
\hline Females vs. males & $1.21(0.83-1.77)$ & $1.14(0.77-1.70)$ \\
\hline \multicolumn{3}{|l|}{ Education } \\
\hline High vs. low education & $1.09(0.77-1.53)$ & $1.09(0.76-1.55)$ \\
\hline \multicolumn{3}{|l|}{ Smoking status } \\
\hline Daily vs. occasional smoking & $0.99(0.63-1.55)$ & $1.09(0.51-2.32)$ \\
\hline \multicolumn{3}{|l|}{ Cigarettes per week (CPW) } \\
\hline 21-70 CPW vs. 20 or less CPW & $0.63(0.35-1.10)$ & $0.54(0.24-1.19)$ \\
\hline 71 or more CPW vs. 20 or less CPW & $0.98(0.60-1.60)$ & $0.83(0.38-1.80)$ \\
\hline \multicolumn{3}{|l|}{ Plan to quit or reduce } \\
\hline Plan to quit vs. plan to reduce & $1.82(1.07-3.10)$ & $1.75(1.01-3.04)$ \\
\hline \multicolumn{3}{|l|}{ Quit attempts last 12 months } \\
\hline 1 vs. none & $1.32(0.75-2.41)$ & $1.24(0.68-2.27)$ \\
\hline 2 or more vs. none & $1.51(0.84-2.70)$ & $1.51(0.82-2.78)$ \\
\hline
\end{tabular}

smokers preferring NRT, e-cigarettes, and smoking cessation medication [30-32]. However, a study from 27 EU Member States found that younger smokers were more likely to have used e-cigarettes for smoking cessation [19].

The observed association between the number of quit attempts and the use of a cessation app is supported by others $[25,33]$. The constant reminding and stimulation in a quitting process that the cessation apps provide may stimulate quit attempts, although the causal direction is not known. Further investigation of the preferences for using cessation apps and of the reasons for the association between quit attempts and the use of a mobile app is warranted.

Established smokers may prefer a smoking cessation method that handles both abstinence and nicotine dependence and replace an established habit of cigarette smoking with the activity of vaping $[34,35]$. This assumption is supported by our findings that daily smokers and those with high cigarette consumption per week have higher odds of using NRT and prescription medication. The lack of an association between high-consuming cigarette smokers and e-cigarettes may be explained by the fact that nicotine-containing eliquid is not permitted to be sold in Norway or that ecigarette users are more likely to reduce their consumption and make a switch in their smoking status from daily to occasional smoking.

There are several smoking cessation apps on the market, but their effectiveness for successful smoking cessation is inconclusive [36]. Some single studies have found effects [37-39]. Their potential as a tool in smoking cessation is considered to be high, with low cost, high reach, and a "choice architecture" potential, i.e., they are capable of influencing individual decision-making in social environments where choices need to be made [40]. The nudge approach to health behavior change highlights "choice architecture," individual autonomy, and simplicity in behavioral change [41, 42]. Studies on smoking cessation applications are constantly evolving, and the use of smart technology such as the possibility of detecting smoking in real time may be an effective tool for increasing success rates $[43,44]$.

NRTs have been on the market for a long time, with a variety of available product types. They are easily accessible, easy to use, and considered safe for most adults, even for longterm use [45]. The Norwegian guidelines on smoking cessation suggest minimal intervention, including advice to use pharmacotherapy (NRT or prescription medication). The sale of nicotine replacement products, both in pharmacies and over the counter, increased from 2015 to 2019 [46]. The effect of NRTs in smoking cessation is considered high in treatment settings, particularly among heavy smokers, but their realworld effectiveness is disputable [47-49].

Smokers' choices of cessation methods seem to reflect the recommendations made by the health authorities and health personnel regarding NRTs and the smoking cessation app, but not e-cigarettes. The Norwegian tobacco policy on ecigarettes as a smoking cessation method is in line with the WHO's approach, and the recommendation for e-cigarette use in smoking cessation has been categorized as "precautionary nonuse" [50]. The Norwegian government's tobacco control strategy does not dismiss the idea of a harm reduction perspective [51]. However, e-cigarettes are not recommended as a smoking cessation method in the national guidelines on smoking cessation [52]. In that light, the number of smokers reporting e-cigarettes as a smoking cessation method may be seen as high.

The prevalence of e-cigarette use in Norway is low, and use is most prevalent among current and former smokers [1]. The evidence for e-cigarettes' role in smoking cessation is increasing and may explain the high use of e-cigarettes as 
a smoking cessation method in our sample of help-seeking smokers [15, 19, 53]. Another explanation for the relatively high use of e-cigarettes in our study may be related to an incident at the start of the study, where the owner of a vaping website promoted the present study to its members. This promotion was removed on our recommendation and would therefore have influenced the first part of the data collection only. This incident may have led to artificially high numbers of smokers using e-cigarettes as a cessation method in the study.

Although e-cigarettes containing nicotine are not yet on the market in Norway and e-cigarettes are not included in the governmental toolbox of smoking cessation methods, information about e-cigarettes is highly visible in a variety of media channels, from user organizations, vape shops, webshops, and by word of mouth $[54,55]$. The availability of ecigarettes, including nicotine e-liquid at cross-border shopping sites and online, and its affordability may explain the relatively high use among smokers planning to quit.

Few respondents in this sample used snus as a smoking cessation method. This finding stands in contrast to previous findings on former male smokers in Norway, where snus was the most used method to quit [27]. One possible explanation is selection bias. Due to the self-recruitment strategy, the sample is not representative of Norwegian smokers.

\section{Limitations}

A limitation of this study is that the findings may not apply to the general population of smokers in Norway (see Supplementary Materials, Table 5). The study sample is a convenient sample of help-seeking smokers. Although the recruitment was from two different platforms, very few were recruited from the quit line. One possible explanation is the difference in total visits, with 190000 visitors on the website in 2014, while less than 10000 called the quit line in the same year. Those who were invited from the quit line were also given the opportunity of a postal survey, although very few opted for this solution. The majority were recruited from the website, and recruitment was thereby restricted to those who were able to complete an online survey.

Receiving advice from health care professionals is often included as an important part of the cessation aid toolbox, but that was not addressed in the present study.

\section{Conclusions}

The majority of the study participants in the current study used NRTs, a smoking cessation app, or e-cigarettes as methods for smoking cessation. Older smokers were more likely to use NRTs and e-cigarettes, while younger smokers were more likely to use the smoking cessation app. Females were more likely to use the cessation app, and males more likely to use snus. E-cigarette use was more common among smokers with low educational level. This knowledge is relevant for further work in smoking cessation planning and policies.

\section{Data Availability}

Data are available upon reasonable request.

\section{Ethical Approval}

The authors assert that all procedures contributing to this work comply with the ethical standards of the relevant national and international committees on human experimentation and with the Helsinki Declaration of 1975, as revised in 2008 .

\section{Conflicts of Interest}

The authors declare no conflict of interest regarding the publication of this paper.

\section{Acknowledgments}

We gratefully acknowledge the contributions to the study of the Norwegian Directorate of Health and Norfakta Markedsanalyse AS (data collection). The study was funded by the Norwegian Institute of Public Health and Norwegian Directorate of Health.

\section{Supplementary Materials}

Supplementary Materials are added: Appendix table, an overview of the listed smoking cessation methods, and Table 5, an overview over the total sample, including population numbers (link). (Supplementary Materials)

\section{References}

[1] E. Kvaavik, Tobakk i Norge [Tobacco in Norway], 2018, http://hdl.handle.net/11250/2582061.

[2] A. Bakken, Ungdata 2020. Nasjonale resultater. [Youth research 2020.], Norwegian Social Research-NOVA, Oslo, 2020.

[3] L. Joossens, A. Feliu, and E. Fernandez, "The tobacco control scale 2019 in Europe," in Association of European Cancer Leagues, Catalan Institute of Oncology, Brussels, 2020.

[4] M. Lund, "Social inequality in cigarette consumption, cigarette dependence, and intention to quit among Norwegian smokers," BioMed Research International, vol. 2015, no. Special Issue, Article ID 835080, 2015.

[5] L. Ranney, C. Melvin, L. Lux, E. McClain, and K. N. Lohr, "Systematic review: smoking cessation intervention strategies for adults and adults in special populations," Annals of Internal Medicine, vol. 145, no. 11, pp. 845-856, 2006.

[6] J. N. Soulakova and L. J. Crockett, "Unassisted quitting and smoking cessation methods used in the United States: analyses of 2010-2011 tobacco use supplement to the current population survey data," Nicotine \& Tobacco Research, vol. 20, no. 1, pp. 30-39, 2016.

[7] S.-H. Zhu, T. Melcer, J. Sun, B. Rosbrook, and J. P. Pierce, "Smoking cessation with and without assistance: a population-based analysis," American Journal of Preventive Medicine, vol. 18, no. 4, pp. 305-311, 2000.

[8] C. Notley, S. Gentry, J. Livingstone-Banks, L. Bauld, R. Perera, and J. Hartmann-Boyce, "Incentives for smoking cessation," Cochrane Database of Systematic Reviews, vol. 7, 2019.

[9] T. Benmarhnia, J. P. Pierce, E. Leas et al., "Can E-cigarettes and pharmaceutical aids increase smoking cessation and reduce cigarette consumption? Findings from a nationally 
representative cohort of American smokers," American Journal of Epidemiology, vol. 187, no. 11, pp. 2397-2404, 2018.

[10] D. Kotz, M. Böckmann, and S. Kastaun, "The use of tobacco, E-cigarettes, and methods to quit smoking in Germany," Deutsches Arzteblatt international, vol. 115, no. 14, pp. 235242, 2018.

[11] R. Tokle, Elektroniske sigaretter. Bruksmønster, brukergrupper og brukerkultur, in SIRUS rapport, Statens Institutt for Rusmiddelforskning Oslo, 2014.

[12] K. Lund, "Tobacco harm reduction in the real world: has the availability of snus in Norway increased smoking cessation?," Drugs and Alcohol Today, vol. 13, no. 2, 2013.

[13] L. Ramström, R. Borland, and T. Wikmans, "Patterns of smoking and snus use in Sweden: implications for public health," International Journal of Environmental Research and Public Health, vol. 13, no. 11, p. 1110, 2016.

[14] K. Cahill, S. Stevens, R. Perera, and T. Lancaster, "Pharmacological interventions for smoking cessation: an overview and network meta-analysis," Cochrane Database of Systematic Reviews, vol. 5, Art No. CD009329, 2013.

[15] J. Hartmann-Boyce, H. McRobbie, N. Lindson et al., "Electronic cigarettes for smoking cessation," Cochrane Database of Systematic Reviews, vol. 10, Art No. CD010216, 2020.

[16] P. Hajek, A. Phillips-Waller, D. Przulj et al., "A randomized trial of E-cigarettes versus nicotine-replacement therapy," New England Journal of Medicine, vol. 380, no. 7, pp. 629637, 2019.

[17] N. Lindson, S. C. Chepkin, W. Ye, T. R. Fanshawe, C. Bullen, and J. Hartmann-Boyce, "Different doses, durations and modes of delivery of nicotine replacement therapy for smoking cessation," Cochrane Database of Systematic Reviews, vol. 4, Art No. CD013308, 2019.

[18] A. L. Graham and M. S. Amato, "Twelve million smokers look online for smoking cessation help annually: health information national trends survey data, 2005-2017," Nicotine \& Tobacco Research, vol. 21, no. 2, pp. 249-252, 2019.

[19] F. T. Filippidis, A. A. Laverty, U. Mons, C. Jimenez-Ruiz, and C. I. Vardavas, "Changes in smoking cessation assistance in the European Union between 2012 and 2017: pharmacotherapy versus counselling versus e-cigarettes," Tobacco Control, vol. 28, no. 1, pp. 95-100, 2019.

[20] C. Enyioha, C. Meernik, L. Ranney, A. O. Goldstein, K. Sellman, and C. E. Kistler, "Willingness-to-try various tobacco cessation methods among US adult cigarette smokers," Tobacco prevention \& cessation, vol. 5, p. 18, 2019.

[21] J. L. Westmaas, L. Abroms, J. Bontemps-Jones, J. E. Bauer, and J. Bade, "Using the Internet to understand smokers' treatment preferences: informing strategies to increase demand," Journal of Medical Internet Research, vol. 13, no. 3, article e58, 2011.

[22] R. W. Paterson, K. J. Boyle, C. F. Parmeter, J. E. Neumann, and P. de Civita, "Heterogeneity in preferences for smoking cessation," Health Economics, vol. 17, no. 12, pp. 1363-1377, 2008.

[23] J. Marti, "Assessing preferences for improved smoking cessation medications: a discrete choice experiment," The European Journal of Health Economics, vol. 13, no. 5, pp. 533-548, 2012.

[24] N. Jayakumar, M. Chaiton, B. Zhang, P. Selby, and R. Schwartz, "Sex differences in use of smoking cessation services and resources: a real-world study," Tobacco Use Insights, vol. 13, pp. 1-8, 2020.

[25] S. K. L. Chevalking, S. Ben Allouch, M. Brusse-Keizer, M. G. Postel, and M. E. Pieterse, "Identification of users for a smok- ing cessation mobile app: quantitative study," Journal of Medical Internet Research, vol. 20, no. 4, article e118, 2018.

[26] P. H. Smith, K. A. Kasza, A. Hyland et al., "Gender differences in medication use and cigarette smoking cessation: results from the international tobacco control four country survey," Nicotine \& Tobacco Research, vol. 17, no. 4, pp. 463-472, 2015.

[27] J. Scheffels, K. E. Lund, and A. McNeill, "Contrasting snus and NRT as methods to quit smoking. An observational study," Harm Reduction Journal, vol. 9, no. 1, p. 10, 2012.

[28] M. Lucherini, S. Hill, and K. Smith, "Potential for noncombustible nicotine products to reduce socioeconomic inequalities in smoking: a systematic review and synthesis of best available evidence," BMC Public Health, vol. 19, no. 1, p. 1469, 2019.

[29] S. Gentry, N. G. Forouhi, and C. Notley, "Are electronic cigarettes an effective aid to smoking cessation or reduction among vulnerable groups? A systematic review of quantitative and qualitative evidence," Nicotine \& Tobacco Research, vol. 21, no. 5, pp. 602-616, 2019.

[30] W. T. Hung, D. Perez, T. Cotter, and T. Cotter, "Use and perceived helpfulness of smoking cessation methods: results from a population survey of recent quitters," BMC Public Health, vol. 11, no. 1, p. 592, 2011.

[31] S. E. Jackson, D. Kotz, R. West, and J. Brown, "Moderators of real-world effectiveness of smoking cessation aids: a population study," Addiction, vol. 114, no. 9, pp. 1627-1638, 2019.

[32] T.-H. T. Vu, J. L. Hart, A. Groom et al., "Age differences in electronic nicotine delivery systems (ENDS) usage motivations and behaviors, perceived health benefit, and intention to quit," Addictive Behaviors, vol. 98, p. 106054, 2019.

[33] N. F. BinDhim, K. McGeechan, and L. Trevena, "Who uses smoking cessation apps? A feasibility study across three countries via smartphones," JMIR mHealth and uHealth, vol. 2, no. 1, article e4, 2014.

[34] S. Zare, M. Nemati, and Y. Zheng, "A systematic review of consumer preference for e-cigarette attributes: flavor, nicotine strength, and type," PLoS One, vol. 13, no. 3, article e0194145, 2018.

[35] C. Notley, E. Ward, L. Dawkins, and R. Holland, "The unique contribution of e-cigarettes for tobacco harm reduction in supporting smoking relapse prevention," Harm Reduction Journal, vol. 15, no. 1, p. 31, 2018.

[36] A. Barnett, I. Yang, K. Hay et al., "A meta-analysis of the effectiveness of smart phone applications to aid smoking cessation," European Respiratory Journal, vol. 54, article OA5134, Supplement 63, 2019.

[37] N. F. BinDhim, K. McGeechan, and L. Trevena, "Smartphone smoking cessation application (SSC app) trial: a multicountry double-blind automated randomised controlled trial of a smoking cessation decision-aid 'app'," BMJ Open, vol. 8, no. 1, article e017105, 2018.

[38] F. G. Sanchez, L. C. Hernández, F. N. Benjumea et al., "Use of a mobile app to give up smoking. Results from a clinical trial," European Respiratory Journal, vol. 54, article PA2237, Supplement 63, 2019.

[39] M. Pallejà-Millán, C. Rey-Reñones, M. L. Barrera Uriarte et al., "Evaluation of the Tobbstop mobile app for smoking cessation: cluster randomized controlled clinical trial," JMIR mHealth and uHealth, vol. 8, no. 6, article e15951, 2020.

[40] M. Quigley, "Nudging for health: on public policy and designing choice architecture," Medical law review, vol. 21, no. 4, pp. 588-621, 2013. 
[41] M. Weinmann, C. Schneider, and J. . Brocke, "Digital nudging," Business \& Information Systems Engineering, vol. 58, no. 6, pp. 433-436, 2016.

[42] G. J. Hollands, T. M. Marteau, S. A. Jebb et al., “Altering micro-environments to change population health behaviour: towards an evidence base for choice architecture interventions," BMC Public Health, vol. 13, no. 1, p. 1218, 2013.

[43] J. Lüscher, C. Berli, P. Schwaninger, and U. Scholz, "Smoking cessation with smartphone applications (SWAPP): study protocol for a randomized controlled trial," BMC Public Health, vol. 19, no. 1, p. 1400, 2019.

[44] C. Morriscey, A. Shephard, A. van Houdt, D. Kerr, and S. P. Barrett, "Using 'smart' technology to aid in cigarette smoking cessation: examining an innovative way to monitor and improve quit attempt outcomes," Journal of Smoking Cessation, vol. 14, no. 3, pp. 149-154, 2019.

[45] M. C. Fiore, C. R. Jaén, T. B. Baker et al., Treating tobacco use and dependence: 2008 update, U.S. Department of Health and Human Services, Rockville (MD), 2008.

[46] H. Sommerschild, "Drug consumption in Norway 2015-2019," in Data from Norwegian Drug Wholesales Statistics and the Norwegian Prescription Database, in Legemiddelstatistikk, Norwegian Institute for Public Health (NIPH), Oslo, Norway, 2020.

[47] J. P. Pierce and E. A. Gilpin, "Impact of over-the-counter sales on effectiveness of pharmaceutical aids for smoking cessation," JAMA, vol. 288, no. 10, pp. 1260-1264, 2002.

[48] E. C. Leas, J. P. Pierce, T. Benmarhnia et al., "Effectiveness of pharmaceutical smoking cessation aids in a nationally representative cohort of American smokers," Journal of the National Cancer Institute, vol. 110, no. 6, pp. 581-587, 2017.

[49] D. Kotz, J. Brown, and R. West, "'Real-world' effectiveness of smoking cessation treatments: a population study," Addiction, vol. 109, no. 3, pp. 491-499, 2014.

[50] B. R. Brady, J. S. de la Rosa, U. S. Nair, and S. J. Leischow, "Electronic cigarette policy recommendations: a scoping review," American Journal of Health Behavior, vol. 43, no. 1, pp. 88-104, 2019.

[51] Ministry of Health and Care Services, Public health report- $a$ good life in a safe society. Short version, White Paper No.19, Oslo, Norway, 2020.

[52] Norwegian Directorate of Health, Retningslinjer for røykeavvenning [Guidelines for smoking cesstion], Oslo, Norway, 2016.

[53] K. E. Farsalinos and R. Niaura, "E-cigarettes and smoking cessation in the United States according to frequency of Ecigarette use and quitting duration: analysis of the 2016 and 2017 national health interview surveys," Nicotine \& Tobacco Research, vol. 22, no. 5, pp. 655-662, 2019.

[54] S. L. Emery, L. Vera, J. Huang, and G. Szczypka, "Wanna know about vaping? Patterns of message exposure, seeking and sharing information about e-cigarettes across media platforms," Tobacco Control, vol. 23, Supplement 3, p. iii17, 2014.

[55] L. Collins, A. M. Glasser, H. Abudayyeh, J. L. Pearson, and A. C. Villanti, "E-cigarette marketing and communication: how E-cigarette companies market E-cigarettes and the public engages with E-cigarette information," Nicotine \& Tobacco Research, vol. 21, no. 1, pp. 14-24, 2019. 